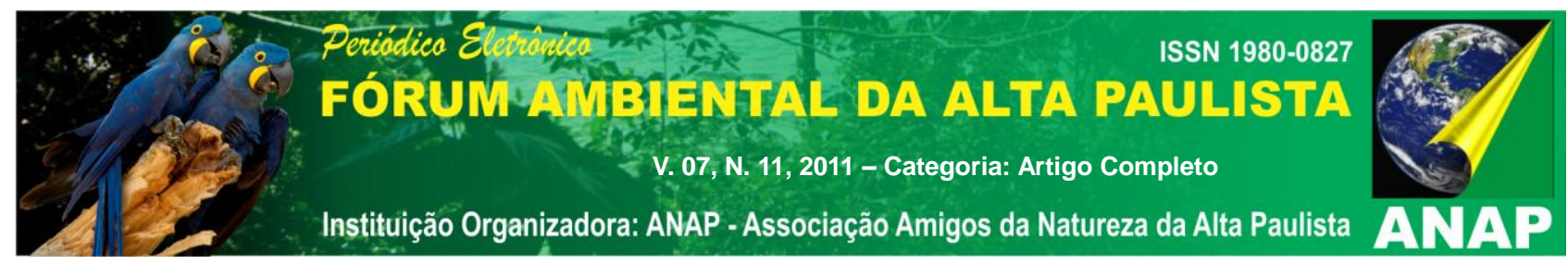

\title{
CIÊNCIA DE SERVIÇOS NO BRASIL: PROPOSTA DE APLICAÇÃO AOS AGRONEGÓCIOS
}

Matheus Borela ${ }^{1}$

Camila Pires Cremasco ${ }^{2}$

Luís Roberto Almeida Gabriel Filho ${ }^{3}$

Luiz Roberto Almeida Gabriel ${ }^{4}$

RESUMO: Ao se verificar nas últimas décadas a composição dos setores econômicos nos chamados países desenvolvidos e em desenvolvimento, nota-se um grande avanço e predominância do setor de serviços na composição de seu Produto Interno Bruto, chegando a ser na maioria dos casos o mais importante setor gerador de divisas, emprego e desenvolvimento. A Ciência de Serviços (CS) traz hoje a necessidade estratégica de políticas públicas, de ensino profissional e de pesquisas para o fomento e desenvolvimento desta Ciência no Brasil como fator estratégico para garantir uma maior competitividade da economia brasileira. A partir da hipótese de utilização da CS e de uma revisão bibliográfica do tema, buscou-se evidenciar suas potenciais aplicações no agronegócio, de maneira que este se torne mais eficiente, coordenado e sincronizado com o avanço dos serviços na composição da economia contemporânea nacional.

Palavras-Chave: Ciência de Serviços, serviços, agronegócios.

\footnotetext{
${ }^{1}$ Bacharel em Administração, UNESP - Univ. Estadual Paulista, Campus de Tupã, matheusbps@gmail.com.

2 Professor Assistente, FATEC - Faculdade de Tecnologia, Presidente Prudente, camila@fatecpp.edu.br

3 Professor Assistente Doutor, UNESP - Univ. Estadual Paulista, Campus de Tupã, gabrielfilho@tupa.unesp.br.

${ }^{4}$ Professor Adjunto, UNESP - Univ. Estadual Paulista, Faculdade de Ciências e Tecnologia, Campus de

Presidente Prudente, gabriel@fct.unesp.br.
} 


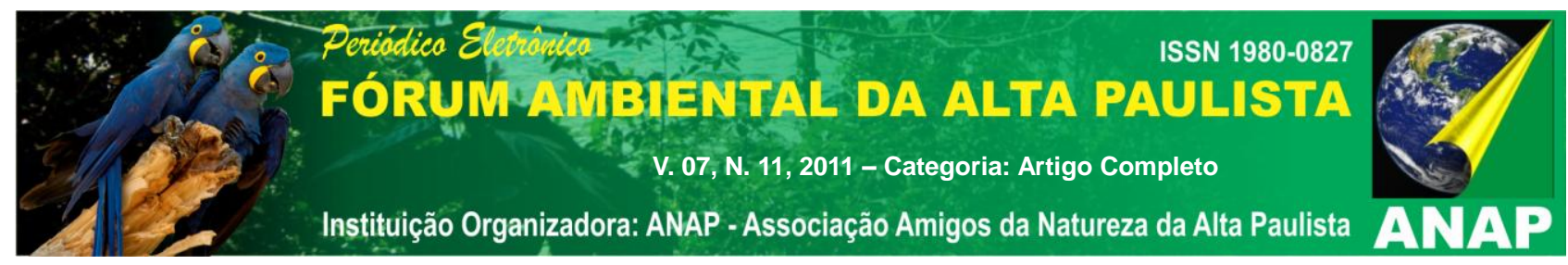

\section{INTRODUÇÃo}

É notória a crescente demanda por serviços no Brasil e na economia mundial. Tal demanda sobe a proporções semelhantes ao crescimento da população mundial, com 6,9 bilhões de habitantes segundo o U.S. Census Bureau, Population Division (2011). A situação evidencia-se na consolidação deste setor ao se analisar os mercados emergentes, com destaque para os chamados BRICs (Brasil, Rússia, Índia e China) que já se nota uma tendência de predominância.

A crescente demanda por serviços tem como sua gênese o amadurecimento das economias desenvolvidas e o crescimento recente dos países em desenvolvimento, estes seguindo tendência semelhante na dinâmica de formação dos setores econômicos nacionais, migrando de uma predominância do setor primário (agrícola) à superioridade do setor terciário sobre a indústria e a agricultura.

Apesar da importância e presença do terceiro setor nas economias tidas como globalizadas e em desenvolvimento, ainda não se verifica um completo e especial destaque à sua utilização e relevância enquanto também um fenômeno socioeconômico cada vez mais atual e evidentemente passível de observação, estudo e, por conseguinte, criação de hipóteses que o modifiquem podendo este ser considerado como uma Ciência presente e essencial para as relações humanas. Mesmo tendo o tema serviços como um assunto já constantemente explorado e debatido nas áreas de economia e gestão no meio acadêmico e profissional, ainda se verifica tímidas iniciativas com o objetivo de promover a importância de se criar estudos sistêmicos e multidisciplinares para esta nova Ciência, uma vez que sua relevância torna-se justificável, tanto em virtude da emergência da população mundial por serviços que as atenda, bem como da dinamização com que o comércio global toma forma a medida com que um novo país torna-se uma economia de mercado.

Tal recente relevância se nota à medida que asselaram-se as mudanças e elevam-se a complexidade dos serviços mundo a fora, destacando assim no sumário executivo de uma publicação do ano de 2008 sobre inovações em serviços do 


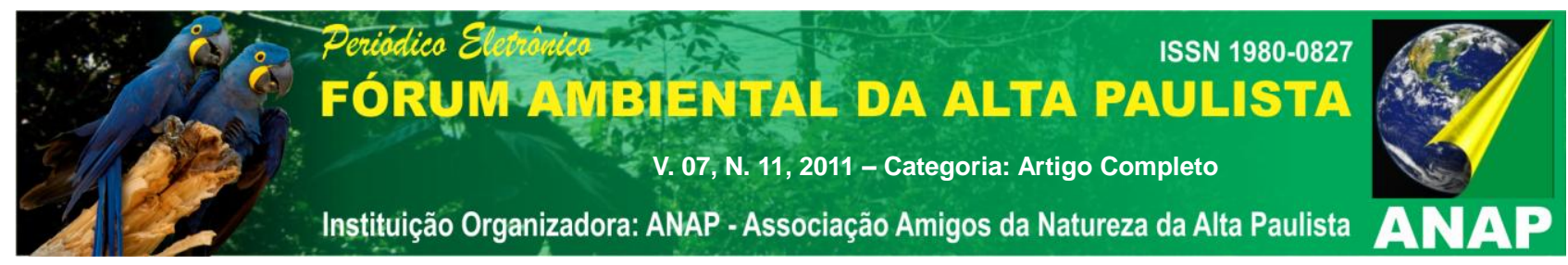

Institute for Manufacturing, University of Cambridge, evidenciando a necessidade de um maior entendimento a respeito deste tema:

\begin{abstract}
"The rising significance of service and the accelerated rate of change mean that service innovation is now a major challenge to practitioners in business and government as well as to academics in education and research. A better understanding of service systems is required" (IfM and IBM, 2008).
\end{abstract}

A aceleração da dinâmica dos serviços na economia mundial já trás reflexos evidentes também para o meio acadêmico que, para Paton e McLaughlin (2008) apud Baraniuk (2009), já pode ser considerada uma disciplina emergente, onde procura mesclar os "fundamentos das teorias científicas, de engenharia, modelos e aplicações voltadas ao campo de gestão, particularmente conhecimento, cadeia de fornecimento e gerenciamento de mudanças, de modo a aumentar e avançar as inovações de serviços" ressaltam os autores.

O objetivo principal deste trabalho é evidenciar através de um cruzamento de informações entre uma revisão bibliográfica das principais obras publicadas no Brasil e no mundo sobre Ciência de Serviços às hipóteses de aplicações desta nova Ciência no importante setor econômico brasileiro, o agronegócio, contribuindo para o aumento de sua competitividade, eficiência e desenvolvimento. Tal proposta de aplicação fixa-se nas relações entre os elos da cadeia do sistema agroindustrial, foco constante de debates e estudos objetivando a redução de perdas, custos, tempo e principalmente a busca por maior coordenação e simetria por toda a cadeia produtiva.

Para tal, elegeu-se como metodologia de pesquisa, a revisão bibliográfica dos principais autores e obras nacionais e internacionais para apresentar os conceitos de Ciência de Serviços presentes atualmente na literatura. Por conseguinte, relaciona-los com hipóteses de aplicação nos agronegócios, para que possa ter uma visão sistêmica do conceito e suas diferentes aplicações.

Agregado a iniciativa de aplicar os conceitos de Ciência de Serviços aos agronegócios, espera-se como fim, a criação de uma linguagem comum, rica, simples e ordenada onde esta perpasse por entre todos os agentes da cadeia agroindustrial com a finalidade de minimizar, através de um estudo multidisciplinar 


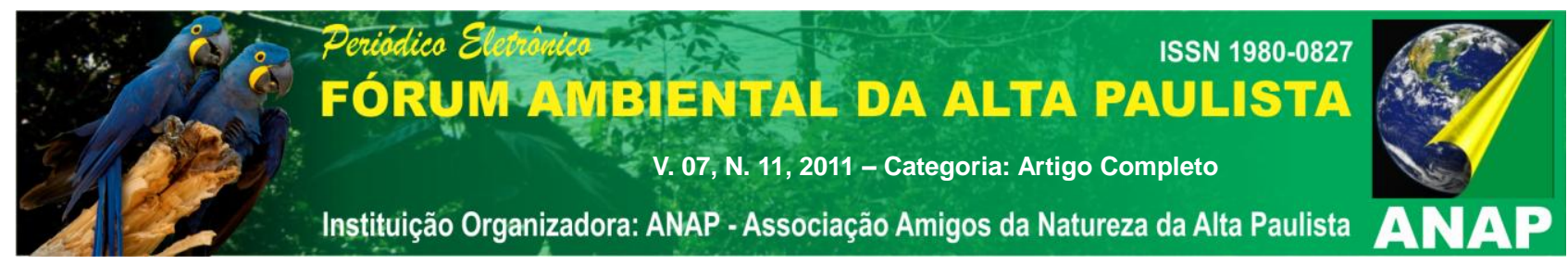

entre gestão, economia, engenharia, design, tecnologia da informação, ciências sociais e computação, os principais entraves ao desenvolvimento do agronegócio no país.

\section{CIÊNCIA DE SERVIÇOS}

Desde os primeiros passos da revisão bibliográfica sobre o tema Ciência de Serviços (CS), houve dificuldade em reunir estudos feitos no Brasil, e até mesmo no exterior, que não tivessem alguma relação com a IBM (International Business Machine), muito por conta de seu pioneirismo em difundir e incentivar quanto por pesquisas como a aplicação desta nova Ciência em modelos de negócios e produtos. Com atuação em cerca de 150 países é considerada por diversos rankings de instituições financeiras e econômicas, como uma das maiores e mais antigas empresas de Tecnologia da Informação do mundo.

No Brasil, através de uma iniciativa de pesquisadores, profissionais e interessados pela área, criou-se em 2009, um site denominado "Ciências de Serviços" 5 , gerido pela Comunidade de Ciência de Serviços com destaque para o Research Scientist da IBM Brazil Claudio Pinhanez, Ph.D. em Media Arts and Sciences no M.I.T. Media Laboratory,1999, onde nota-se seu objetivo público:

"[...] articular e organizar a comunidade de pesquisadores e profissionais em Ciência de Serviços no Brasil. Este website fornece conceitos básicos de Ciência de Serviços, enumera pessoas interessadas na área no Brasil, lista algumas publicações em português e em inglês feitas por pesquisadores brasileiros, e informa sobre sites e recursos disponíveis na Internet" (CIÊNCIA DE SERVIÇOS, on-line, 2011).

Atualmente, verificam-se ao menos três grupos de pesquisa que oficialmente estudam o tema CS na Brasil, são eles:

- DESIS - Design de Serviços e Inovação Social (UFRJ - Universidade Federal do Rio de Janeiro);

\footnotetext{
${ }^{5}$ http://www.cienciadeservicos.com.br/index.htm
} 


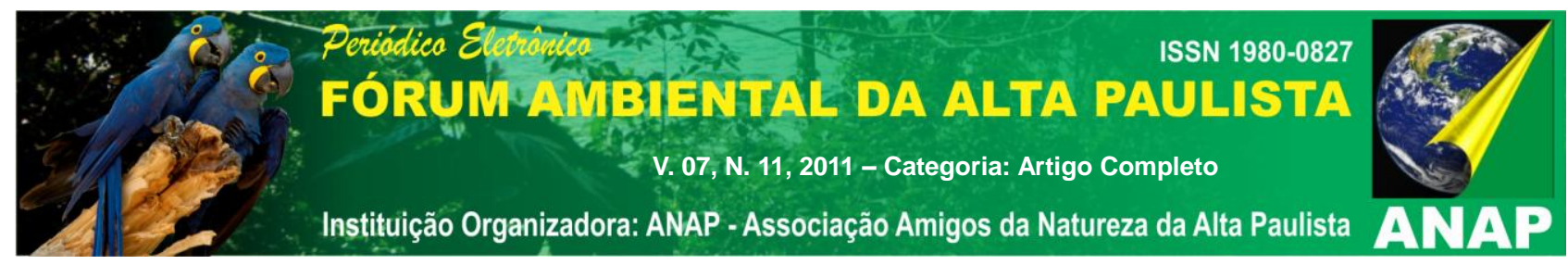

- Laboratório de Pesquisa em Ciências de Serviço (Centro Estadual de Educação Tecnológica Paula Souza - São Paulo);

- PROSICS - Grupo de Pesquisa em Sistemas de Informação e Ciência de Serviços (UNESP - Universidade Estadual Paulista "Júlio de Mesquita Filho", Campus de Bauru-SP).

Notam-se entre tais grupos, diferentes enfoques de CS e inúmeros estudos em aplicações que variam a desde área médica até design e criação de softwares para simulação de serviços.

Em 2009 houve a primeira edição do Workshop de Ciências de Serviços, ocorrido no Campus da UNESP ${ }^{6}$ de Bauru com o apoio institucional da IBM, do Centro Estadual de Educação Tecnológica Paula Souza, do Departamento de Computação e da Faculdade de Ciências do Campus, contando com a presença de importantes pesquisadores da área, ocorrendo novamente no ano seguinte no mesmo local. Seu objetivo principal pautou-se em consolidar os conceitos fundamentais da CS com o intuito de integrar as áreas de conhecimento, além de discutir formas para avançar em direção da definição de uma área englobando serviços inovadores.

2010 foi um importante ano para a CS no Brasil, demonstrando a crescente demanda pelo assunto, resultando na criação do $1^{\circ}$ Simpósio Brasileiro de Ciência de Serviços, ocorrido em Brasília-DF. Tal evento marcou definitivamente a chegada desta nova Ciência, que notadamente buscaram meios para difundi-la e aplica-la na realidade econômica e acadêmica do Brasil, contando com apoios de instituições nacionais e internacionais, além de ser o resultado direto da criação da Comunidade de Ciência de Serviços e sua rede de contatos entre interessados na área pelo Brasil a fora que deram suporte para sua execução em 2010. A proposta central foi a de ampliar o debate também para outros países da América Latina e do Caribe, promovendo simultaneamente o primeiro encontro da Rede Latino-Americana e Caribenha de Pesquisa sobre Serviços (REDLAS), ponto de união entre pesquisadores latino-americanos e caribenhos dedicados aos estudos sobre

\footnotetext{
${ }^{6}$ Universidade Estadual Paulista “Júlio de Mesquita Filho".
} 


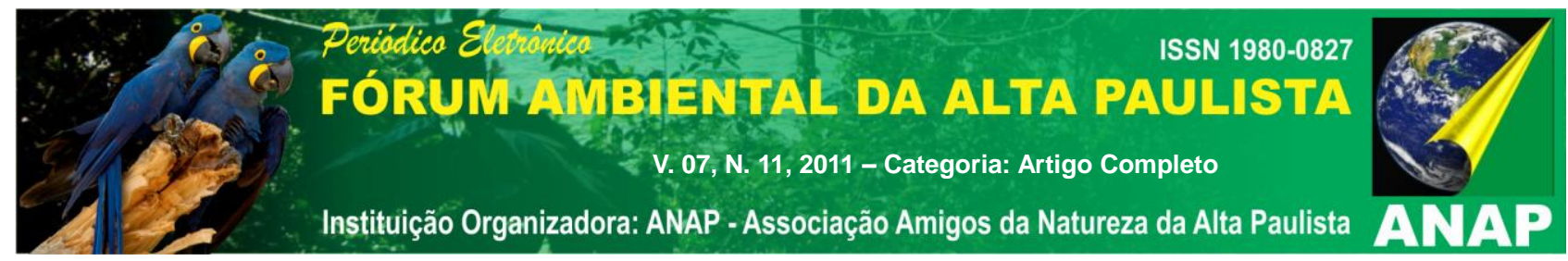

serviços. A REDLAS ${ }^{7}$ já conta com o apoio da RESER - Rede Européia de Pesquisa em Serviços.

De acordo com Baraniuk (2008), outro fator que reforça a importância de pesquisas relacionadas a serviços é a existência de, pelo menos, nove periódicos acadêmicos internacionais especializados na área, que o autor os elenca: o Journal of Service Management (JOSM), antigo International Journal of Service Industry Management (IJSIM); o Journal of Services Marketing (JSM); o Journal of Service Research (JSR); o Managing Service Quality (MSQ); The Service Industries Journal (SIJ); o Journal of Retailing and Consumer Services; o Services Marketing Quarterly; o Managing Service Quality (MSQ); e o Journal of Financial Services Marketing (FSM).

Objetivando trazer os conceitos básicos à tona, segundo a definição encontrada no site da Comunidade de Ciência de Serviços, tem-se que:

"Ciência de Serviços (do inglês Service Science) é a disciplina que estuda de modo sistemático os serviços e sistemas de serviços. Apesar da fundamental importância do setor de serviços na economia, ainda é pouco explorado o estudo sistemático dos diferentes aspectos de serviços e sistemas de serviços, incluindo-se Engenharia, Design, Administração, Economia, Aspectos Humanos e Sociais, e o seu relacionamento com as Artes" (CIÊNCIA DE SERVIÇOS, on-line, 2011).

CS é, deste modo, uma disciplina que "organiza o arcabouço científico para serviços e sistemas de serviços, possibilitando melhorias na eficiência e na qualidade de serviços fundamentadas em métodos acadêmica e cientificamente testados e comprovados" (CIÊNCIA DE SERVIÇOS, on-line, 2011). Enquanto que o design, engenharia, produção, e comercialização de produtos manufaturados é feito utilizando-se métodos, conhecimentos, e técnicas descobertos, desenvolvidos, destaca Cláudio Pinhanez (2009) e amplamente testados ao longo dos dois últimos séculos, a implantação da maioria dos sistemas de serviços é ainda feita, em sua maioria, de uma maneira quase artesanal, baseada na experiência prévia dos implementadores do sistema. Ainda se tratando de sistemas, é de se destacar a íntima - e em muitos casos como citam diversos autores até sendo considerada

\footnotetext{
${ }^{7}$ http:// www.reser.net
} 


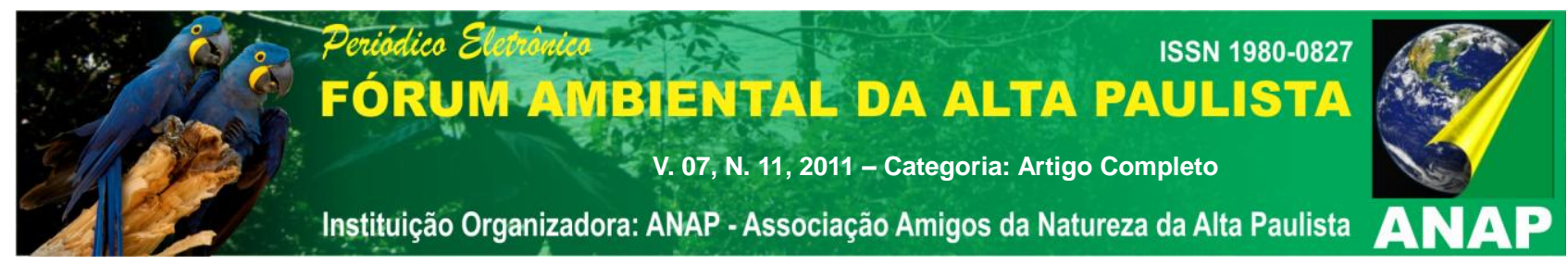

inseparável - relação entre serviços e sistemas. Desta mesma forma, o paper elaborado pelo Institute for Manufacturing da University of Cambridge: "Succeeding through service innovation: A service perspective for education, research, business and government" assim ressalta já em seu sumário executivo:

"Service systems are dynamic configurations of people, technologies, organizations and shared information that create and deliver value to customers, providers and other stakeholders. They form a growing proportion of the world economy and are becoming central to the way businesses, governments, families and individuals work. Innovation, a term applied almost exclusively to technologies in the past, is increasingly used in relation to service systems" (IfM and IBM, 2008)

Enquanto que o uso de sistemas computacionais para simulação e teste virtual de produtos manufaturados é quase que um fato corriqueiro, o modelamento e a simulação de sistemas de serviços é um fato raro, o que leva necessariamente a uma abordagem sistêmica, integrada e com diversas e diferentes óticas, para que se busque um enfoque diferenciado e rico, tanto em termos de eficiência em modelamentos como em aplicações após as simulações criadas no projeto do serviço a ser prestado. Embora ainda faltem entendimentos básicos da dinâmica dos sistemas de serviços, mesmo os limitados conhecimentos científicos disponíveis atualmente são pouco conhecidos pelos profissionais da área (Figura 1). 


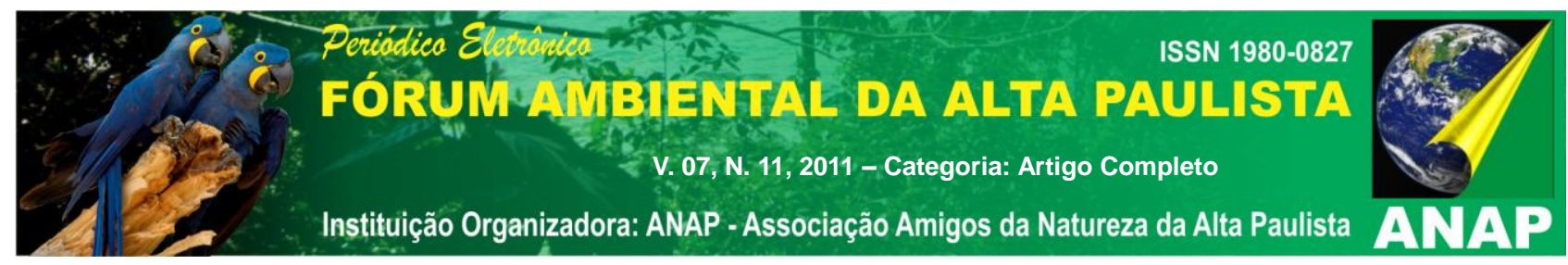

\begin{tabular}{|c|c|c|c|c|}
\hline 1. Emerging demand & 2. Define the domain & 3. Foundations \& gaps & 4. Bridge the gaps & 5. Recommendations \\
\hline \multirow{3}{*}{$\begin{array}{l}\text { Service } \\
\text { Innovation } \\
\text { Growth in service } \\
\text { GDP and jobs }\end{array}$} & $\begin{array}{l}\text { Service } \\
\text { Systems }\end{array}$ & $\begin{array}{l}\text { Service } \\
\text { Science }\end{array}$ & $\begin{array}{l}\text { Stakeholder } \\
\text { Priorities }\end{array}$ & $\begin{array}{l}\text { The white paper } \\
\text { offers a starting } \\
\text { point }\end{array}$ \\
\hline & \multirow{2}{*}{$\begin{array}{l}\text { Customer-provider } \\
\text { interactions that } \\
\text { enable value } \\
\text { cocreation }\end{array}$} & \multirow{2}{*}{$\begin{array}{l}\text { To discover the } \\
\text { underlying principles } \\
\text { of complex service } \\
\text { systems }\end{array}$} & Education & \\
\hline & & & $\begin{array}{l}\text { Skills } \\
\text { \& Mindset }\end{array}$ & $\begin{array}{l}\text { Develop programmes } \\
\text { \& qualifications }\end{array}$ \\
\hline \multirow[b]{2}{*}{$\begin{array}{l}\text { Environmental } \\
\text { friendly \& } \\
\text { sustainable }\end{array}$} & \multirow{3}{*}{$\begin{array}{l}\text { Dynamic } \\
\text { configurations of } \\
\text { resources: people, } \\
\text { technologies, } \\
\text { organisations and } \\
\text { information }\end{array}$} & \multirow{2}{*}{$\begin{array}{l}\text { Systematically create, } \\
\text { scale up and improve } \\
\text { service systems }\end{array}$} & Research & \multirow[b]{2}{*}{$\begin{array}{l}\text { Encourage an } \\
\text { interdisciplinary } \\
\text { approach }\end{array}$} \\
\hline & & & $\begin{array}{l}\text { Knowledge } \\
\& \text { Tools }\end{array}$ & \\
\hline $\begin{array}{l}\text { Urbanisation \& } \\
\text { aging population }\end{array}$ & & $\begin{array}{l}\text { Foundations laid by } \\
\text { existing } \\
\text { disciplines }\end{array}$ & Business & \multirow{4}{*}{$\begin{array}{l}\text { Develop and } \\
\text { improve service } \\
\text { innovation } \\
\text { roadmaps, leading } \\
\text { to a doubling of } \\
\text { R\&D investment in } \\
\text { service education } \\
\text { and research }\end{array}$} \\
\hline \multirow{2}{*}{$\begin{array}{l}\text { Globalisation \& } \\
\text { technology drivers }\end{array}$} & \multirow{2}{*}{$\begin{array}{l}\text { Increasing scale, } \\
\text { complexity and } \\
\text { connectedness of } \\
\text { service systems }\end{array}$} & \multirow{2}{*}{$\begin{array}{l}\text { Progress in academic } \\
\text { studies and practical } \\
\text { tools }\end{array}$} & $\begin{array}{l}\text { Employment } \\
\text { \& Collaboration }\end{array}$ & \\
\hline & & & Government & \\
\hline $\begin{array}{l}\text { Opportunities for } \\
\text { businesses, } \\
\text { govemments and } \\
\text { individuals }\end{array}$ & $\begin{array}{l}B 2 B, B 2 C, C 2 C \text {, } \\
B 2 G, G 2 C, G 2 G \\
\text { service networks }\end{array}$ & $\begin{array}{l}\text { Gaps in knowledge } \\
\text { and skills }\end{array}$ & $\begin{array}{l}\text { Policies } \\
\& \text { investment }\end{array}$ & \\
\hline
\end{tabular}

Glossary of definitions, history and outlook of service research, global trends, and ongoing debate

Figura 1: Glossário de definições, história e visão geral de Ciência de Serviços.

Fonte: IfM and IBM, 2008.

No Brasil, as indústrias de serviços produzem mais de $60 \%$ do PIB e empregam 55\% da população ativa. Não obstante, o setor de serviços não só sofre ao mesmo tempo de baixa produtividade e de baixos índices de inovação como também apresenta um processo de seleção mercadológica de empresas no qual algumas vezes as mais inovadoras não sobrevivem (PINHANEZ, 2009; KUBOTA, 2006).

Fazendo um breve e objetivo resgate conceitual sobre serviços, nota-se semelhantes visões a respeito do tema, onde tem-se como melhores definições para o presente artigo, que:

"Serviço é um ato ou desempenho oferecido por uma parte a outra. Embora o processo possa estar ligado a um produto físico, o desempenho é essencialmente intangível e normalmente não resulta em propriedade de nenhum dos fatores de produção." (LOVELOCK e WRIGHT, 2001, p. 5) 


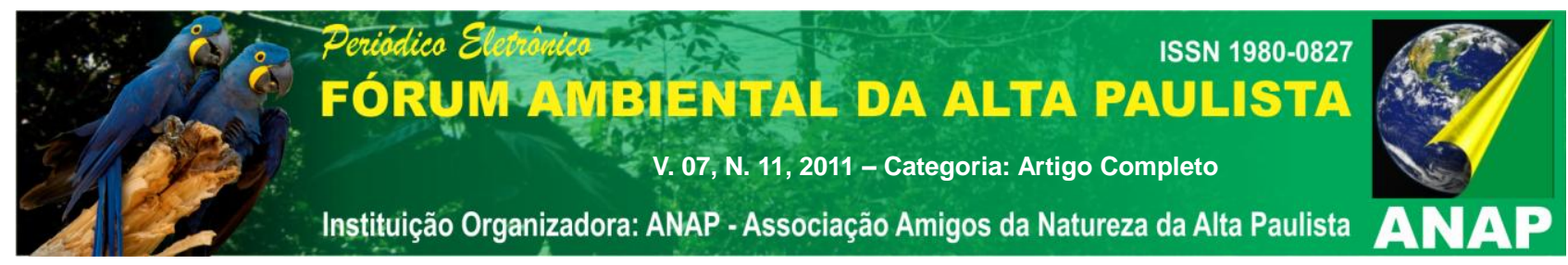

Desta forma, como ressalta Lovelock et al 2001, a ligação entre um produto físico e um serviço, mesmo este não tendo propriedade de nenhum fator de produção, é um elo importante e em muitos casos essencial para o cumprimento da finalidade de um produto. De nada adiantaria se produzir soja, automóveis ou vestimentas sem que houvesse a infraestrutura de serviços para que a produção seja destinada e consumida.

Já Kotler (2000), enfatiza a intangibilidade e a ligação ou não de um serviço a um produto concreto, ou seja, evidencia-se a alienabilidade do serviço frente ao produto e vice-versa:

\begin{abstract}
"Serviço é qualquer ato ou desempenho, essencialmente intangível, que uma parte pode oferecer a outra e que não resulte na propriedade da nada. A execução de um serviço pode estar ou não ligada a um produto concreto." (KOTLER, 2000, p. 448)
\end{abstract}

Assim sendo, verificam-se serviços como sendo a interface entre o produto e o cliente - quando este estiver diretamente e necessariamente relacionado com a venda de um produto, que, para o presente trabalho é relacionado à produção agroindustrial. De tal modo, Pinhanez, 2009 ressalta em seu artigo ${ }^{8}$ destacando as necessidades e oportunidades em CS no Brasil:

"[...] para atender a necessidade de inovação sistemática de serviços da economia brasileira, [...] será preciso haver iniciativos de muito maior porte e ousadia, tanto dos governos e seus agentes como do setor privado. E para tornar concreta a oportunidade de liderança que se vislumbra, serão necessários às nossas lideranças políticas, científicas e empresariais um maior entendimento das transformações que estamos passando e que se refletirão ao longo do século XXI, uma transformação proporcional de atitude e de visão e uma dose considerável de liderança intelectual".

De acordo com David Ing, (2011), o desafio essencial desta nova ciência de sistemas de serviço que está sendo desenvolvido, é repensar as distinções de fabricação, os setores agrícolas e de serviços, bem como os recursos da terra, trabalho e capital, trazendo uma nova leitura de suas relações de dependência, pautando-se em métodos científicos que deem meios para o amadurecimento desta nova ciência para, por conseguinte, se torne parte da realidade da sociedade, da

\footnotetext{
${ }^{8}$ Título: "Educação e pesquisa em ciência de serviços no Brasil: necessidade e oportunidade".
} 


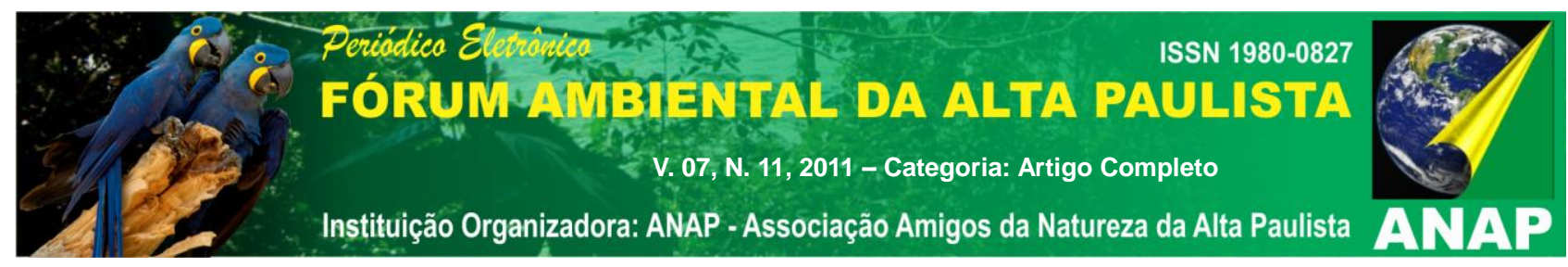

mesma maneira como um carro é testado antes de ser colocado nas ruas.

Para tanto, David Ing (2011), relaciona diversos modelos de negócios, divididos em 6 eixos inter-relacionados, como nota-se na figura 1:

\begin{tabular}{|c|c|c|c|}
\hline & $\begin{array}{l}\text { (a) Organic ethos: } \\
\text { local bounty }\end{array}$ & $\begin{array}{l}\text { (b) Industrial ethos: } \\
\text { machine efficiency }\end{array}$ & $\begin{array}{l}\text { (c) Service ethos: } \\
\text { humility }\end{array}$ \\
\hline $\begin{array}{l}\text { (1) Renewable } \\
\text { resources: } \\
\text { Cultivate and } \\
\text { harvest }\end{array}$ & $\begin{array}{l}\text { (1a) Agroecological } \\
\text { business model } \\
\text { - (Amish) family } \\
\text { farms }\end{array}$ & $\begin{array}{l}\text { (1b) Materials } \\
\text { refining business } \\
\text { model } \\
\text { - Food processing } \\
\text { - Pharmaceuticals }\end{array}$ & $\begin{array}{l}\text { (1c) Physical wellness } \\
\text { business model } \\
\text { - Health care }\end{array}$ \\
\hline $\begin{array}{l}\text { (2) Appropriable } \\
\text { resources: } \\
\text { Acquire and } \\
\text { process }\end{array}$ & $\begin{array}{l}\text { (2a) Handcrafting } \\
\text { business model } \\
\text { - Fashion apparel }\end{array}$ & $\begin{array}{l}\text { (2b) Lean production } \\
\text { business model } \\
\text { - Petrochemicals } \\
\text { - Automobile }\end{array}$ & $\begin{array}{l}\text { (2c) Security business } \\
\text { model } \\
\text { - Insurance } \\
\text { - Banking }\end{array}$ \\
\hline $\begin{array}{l}\text { (3) Cultural } \\
\text { resources: } \\
\text { Affiliate and } \\
\text { practice }\end{array}$ & $\begin{array}{l}\text { (3a) Performative } \\
\text { experience business } \\
\text { model } \\
\text { - Concerts } \\
\text { - Live theatre }\end{array}$ & $\begin{array}{l}\text { (3b) Media } \\
\text { publishing business } \\
\text { model } \\
\text { - News } \\
\text { - Television and } \\
\text { movies }\end{array}$ & $\begin{array}{l}\text { (3c) Intellectual } \\
\text { development business } \\
\text { model } \\
\text { - Education }\end{array}$ \\
\hline
\end{tabular}

Figura 1: Modelos de negócio e pontos de referência em CS. Fonte: David Eng, 2011.

Assim sendo, observa-se que o autor inclui o agribusiness ('1b': figura 1) como também sendo um setor foco para a aplicação desta emergente ciência, abarcando o modelo de recursos naturais e mecânicos como passíveis de redefinição com esta nova interpretação científica voltada para os serviços presentes neste setor:

"The (1b) materials refining business model begins with similar resources to the agroecological, but takes an industrial ethos with the use of machines. Examples include food processed are superhuman speeds, or pharmaceutical development of plant and animal extracts. Corporate agribusiness also follows this type of model" (David Ing, 2011)

Pode-se verificar, desta maneira a grande necessidade de estudo da ciência de serviços e sua fundamental importância em todos os ramos de atividades. 


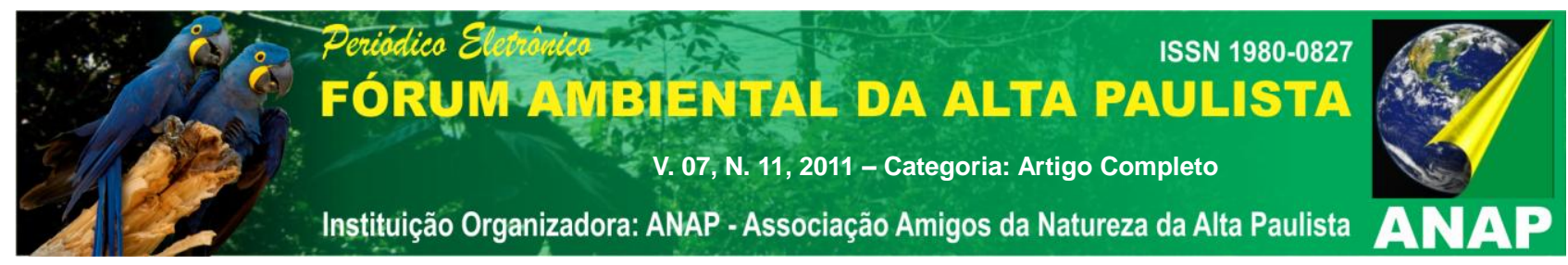

Especificamente, estudos aplicados na área agronegócios constituem uma linha de pesquisa com grandes aplicações. Porém na agricultura, por exemplo, (GUNDERSON et. al., 2009), muitos serviços são necessários, mas não são sistematicamente avaliados de uma forma semelhante a como os produtos são avaliados, surgindo então a necessidade de identificar a compatibilidade de estruturas de qualidade de serviço para o setor de insumos agrícolas.

\section{O AGRONEGÓCIO BRASILEIRO E SUA IMPORTÂNCIA ESTRATÉGICA}

Nota-se no Brasil outro relevante e essencial setor econômico, estratégico tanto do ponto vista fiscal e financeiro, da segurança alimentar às questões profundas como a distribuição fundiária, reforma agrária e os impactos sócio ambientais que possam ser consequentes de suas atividades; trata-se aqui do agronegócio.

A EMBRAPA (Empresa Brasileira de Pesquisa Agropecuária) define o conceito de Agronegócio como sendo "toda relação comercial e industrial envolvendo a cadeia produtiva agrícola ou pecuária". Agronegócio, também chamado de agribusiness, segundo Batalha (2002), é o conjunto de negócios relacionados à agricultura dentro do ponto de vista econômico.

Por outro lado, de acordo com Davis e Goldberg (1957), importantes autores da área, o agronegócio é tratado como sendo:

[...] "a soma total das operações de produção e distribuição de suprimentos agrícolas; das operações de produção na fazenda; do armazenamento, processamento e distribuição dos produtos agrícolas e itens produzidos a partir deles".

O conceito sistêmico apresentado por Davis e Goldenberg procura abarcar todos os vínculos intersetoriais do setor agrícola, deslocando o centro de análise de dentro para fora da fazenda, substituindo a análise parcial dos estudos sobre economia agrícola pela análise holística, ampla da agricultura. Goldberg também ampliou o conceito para incluir, além das relações entre compradores e vendedores, as "influências institucionais", políticas governamentais, mercados futuros e 


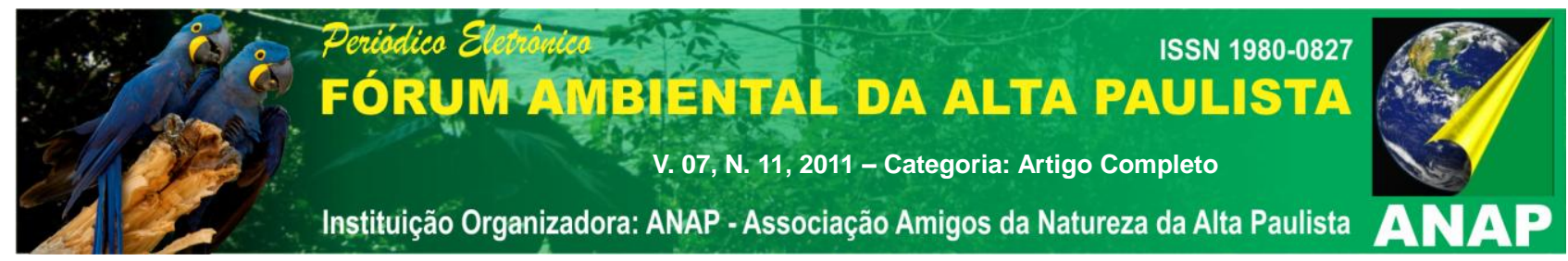

associações comerciais. (Carlos et al, 2009). Como demonstra a Figura 2 o fluxo da cadeia produtiva do Agronegócio.

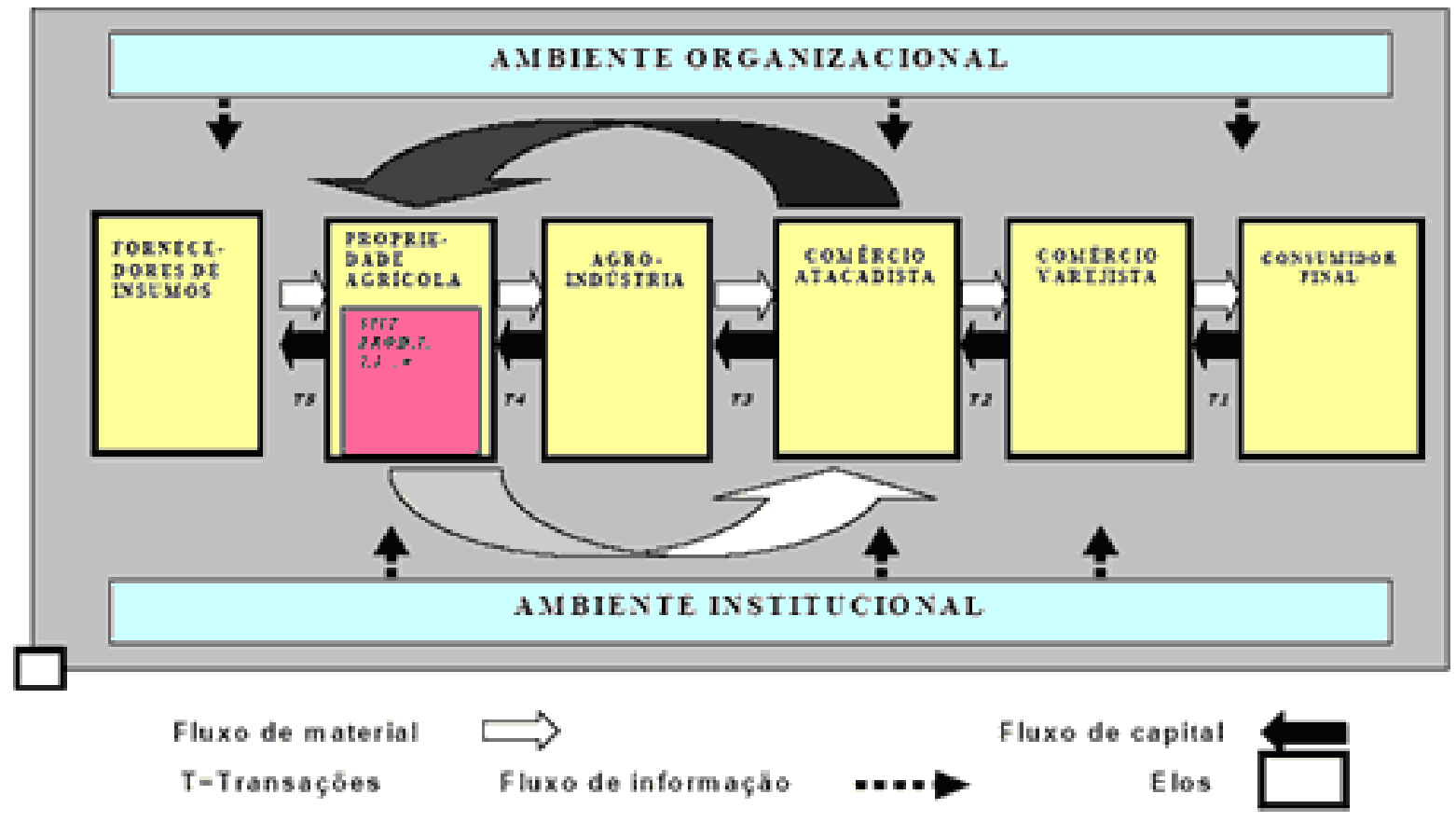

Figura 2: A cadeia produtiva do Agronegócio.

Fonte: CASTRO et al, 2002.

Durante décadas, tal setor fora o principal responsável pelos superávits recentes da balança comercial brasileira - principalmente no atual plano monetário, o real -, tendo uma participação atual na composição do PIB de 23\% (CEPEA/USP, 2011).

Segundo Guilhoto et al. (2006), para o agronegócio familiar brasileiro, as estimativas do PIB e sua evolução mostram que os pequenos agricultores ou os agricultores familiares respondem por parcela expressiva da riqueza nacional, mesmo tendo em vista a insuficiência de terras, as dificuldades creditícias, o menor aporte tecnológico, a fragilidade da assistência técnica e a subutilização da mão-deobra.

Esse quadro pujante decorre, por um lado, da existência de parcelas importantes do segmento familiar integradas aos setores agroindustriais e de distribuição e, de outro, à utilização plena de suas terras. Cabe destacar o quão importante são esses agricultores nas atividades da pecuária de pequeno porte altamente articulada com os setores industriais, na fumicultura e no beneficiamento 


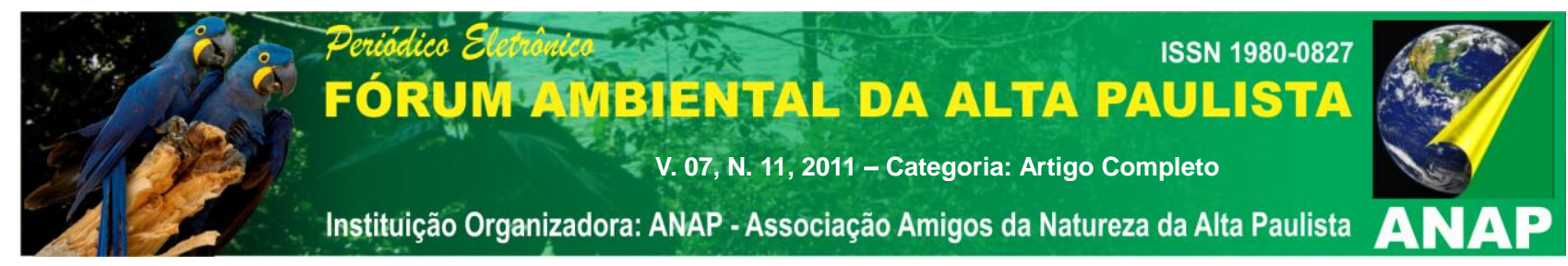

de produtos alimentares. Deste modo, o estudo no setor de serviços nesta área também seria beneficiado. Porém, o foco deveria ser o pequeno agricultor.

$\mathrm{Na}$ Figura 2, nota-se sua evolução ao longo das décadas de 90 e 2000, demonstrando - mesmo com variações em sua participação - sua relevância e notoriedade na geração de empregos e renda (CEPEA/USP, 2011).

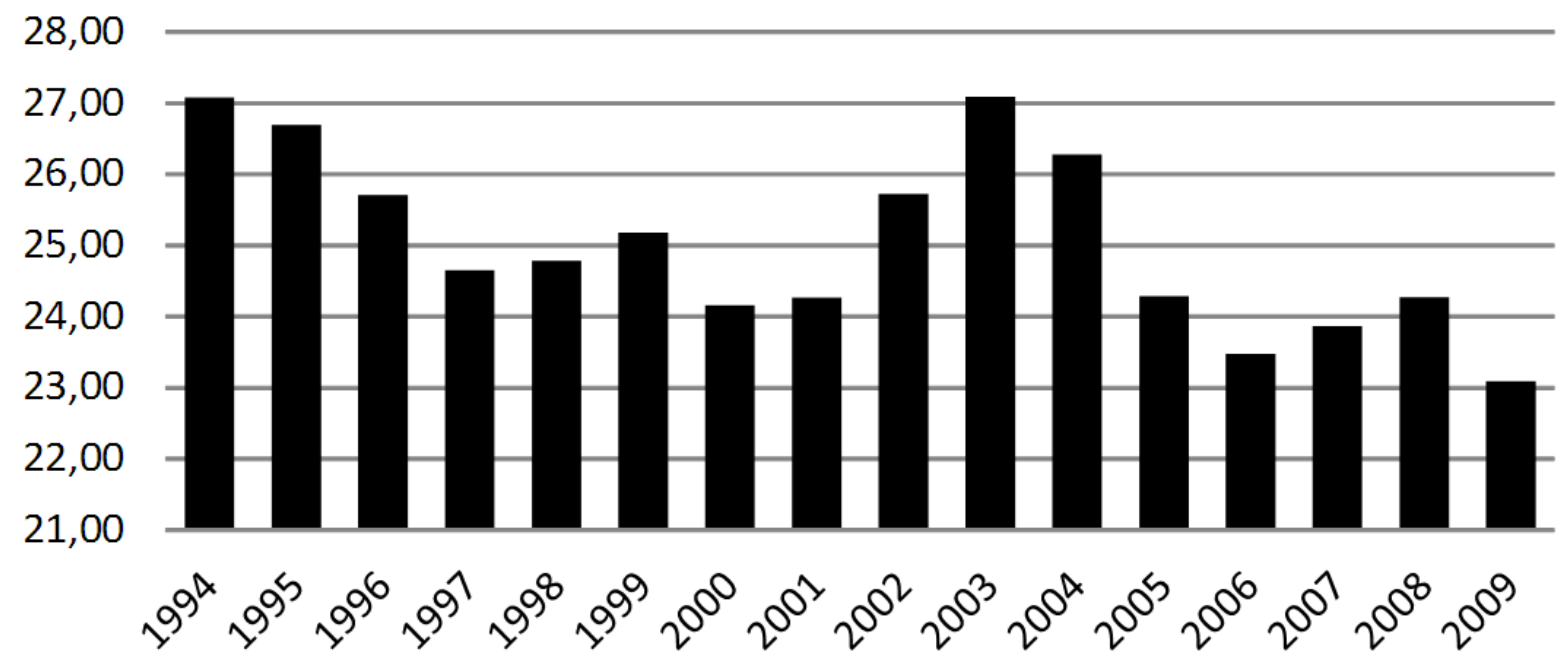

Figura 3: Evolução (em \%) da Participação do Agronegócio no PIB Brasileiro no período de 1994 a 2009.

Fonte: PIB Agronegócio, CEPEA-USP/CNA, 2011.

Em 2010, segundo o MAPA - Ministério da Pecuária, Agricultura e Abastecimento (2011), o setor agropecuário registrou exportações recordes com US\$ 76,4 bilhões. Na comparação com 2009 (US\$ 64,7 bilhões), o valor é 18\% maior e supera em US\$ 4,6 bilhões os US $\$ 71,8$ bilhões registrados, em 2008, até então o mais positivo ano para as vendas externas do agronegócio.

Segundo o MAPA, em seu relatório para as projeções do setor, em 2006 fazendo uma comparação de crescimento entre setores, há duas décadas, mostra que a agropecuária tem sido superior aos setores de indústria e serviços. Nos anos 1990, o crescimento do produto real da agropecuária foi de $2,48 \%$, enquanto industrial cresceu 0,76\% e serviços, 1,37\%. Nessa década, segundo o relatório, 0 PIB da economia cresceu em média $1,73 \%$ ao ano, abaixo do produto da agropecuária. Nos anos 2000, a agropecuária vem tendo um desempenho ainda melhor do que na década de 1990. 


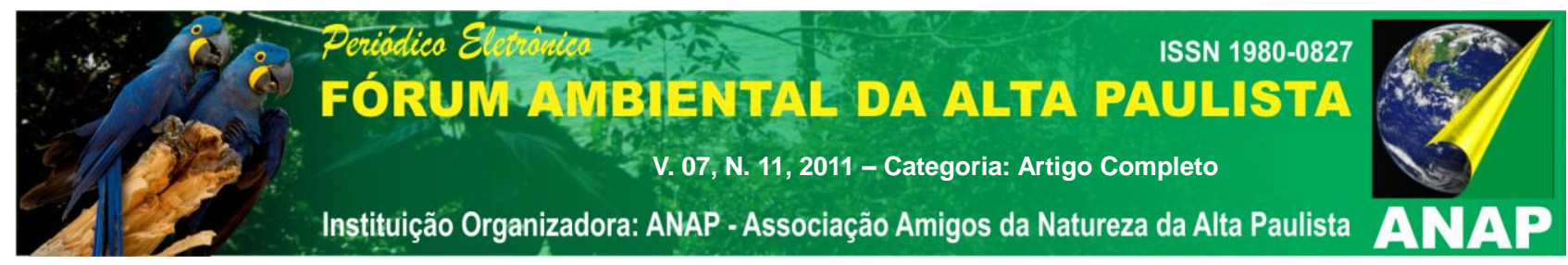

Ao se verificar as exportações, em janeiro de 2011 fora registrado também, crescimento de $35,2 \%$, que passaram de US\$ 9,9 bilhões, em 2009, para US $\$ 13,4$ bilhões em 2010. Sendo assim, observa-se que o superávit da balança comercial do agronegócio alcançou US\$ 63 bilhões ou US\$ 8,1 bilhões superior ao registrado em 2009. Esse saldo foi três vezes maior que os US $\$ 20$ bilhões observados no superávit do comércio global do Brasil no mesmo período segundo o MAPA, 2011.

\section{POTENCIAIS APLICAÇÕES E OPORTUNIDADES DA CS NO AGRONEGÓCIO}

Dentro da cadeia produtiva, no Sistema Agroindustrial (SAI), observam-se diversas aplicações diante da relação básica entre os agentes "comprador $\mathrm{x}$ vendedor". Para melhor definição e foco a fim de delinear as áreas potenciais de aplicação do conceito de Ciências de Serviços nos agronegócios, buscou-se realizar um diagrama com o objetivo de resumir os principais serviços existentes no SAI, bem como também dos serviços comuns que fazem a ligação dos elos entre a compra e a venda. Tais elos são; "logística, transporte e atendimento", como pode-se evidenciar na Figura 3. 

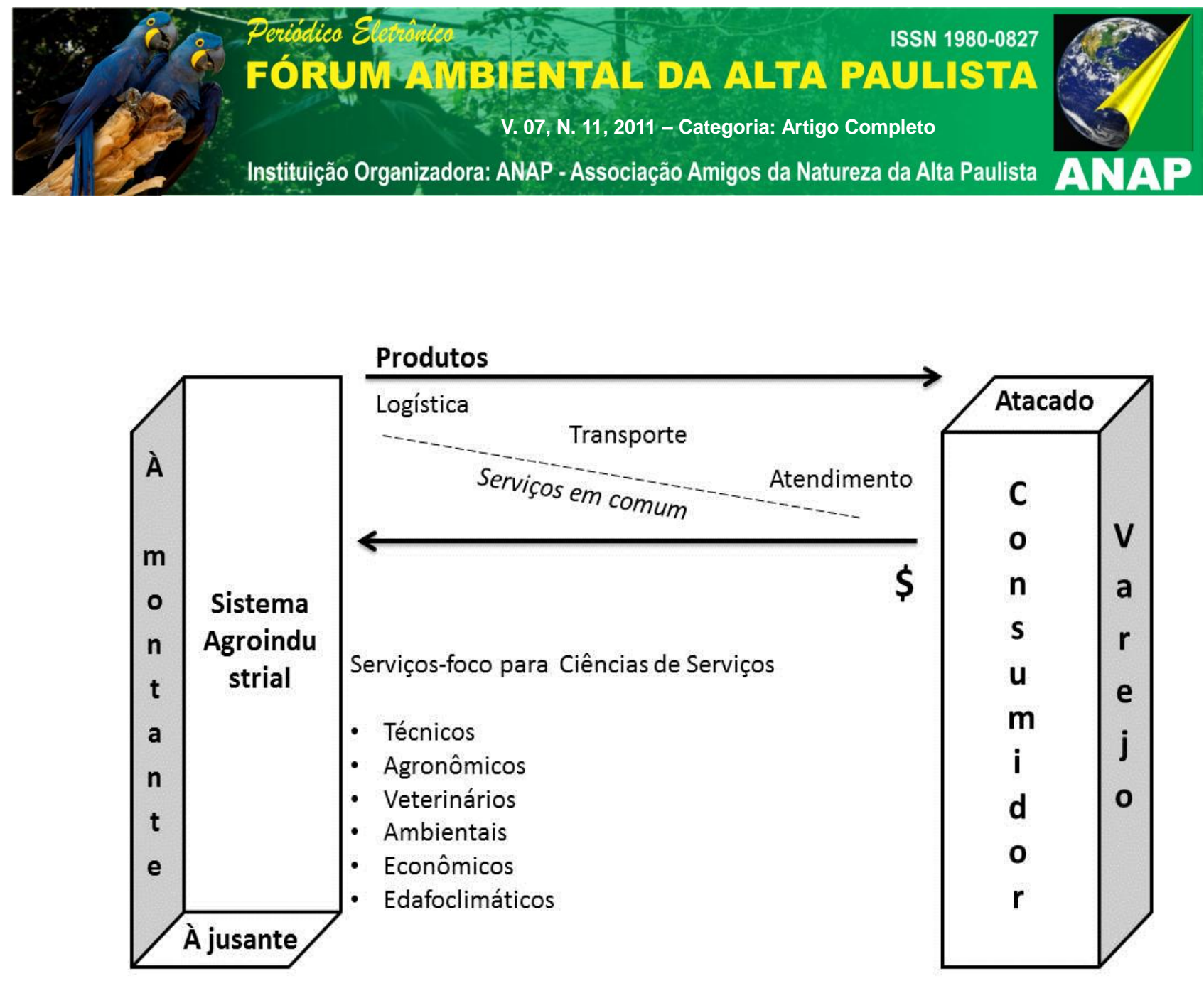

Figura 3: Serviços-foco para a aplicação de Ciências de Serviços nos Agronegócios. Fonte: Elaborado pelos autores.

Alguns fatores estão relacionados ao desempenho do agronegócio brasileiro nos últimos anos e também são indicativos do seu potencial de crescimento. Em uma palestra do Ministro da Agricultura, Roberto Rodrigues, publicada na Revista USP (2005), ele indicou três principais fatores.

O primeiro é a disponibilidade de terras, sendo que nenhum país tem tanto espaço territorial para crescer, e uma fronteira agrícola por avançar, sem que isso represente entrar na Amazônia Legal; o segundo fator apontado é a tecnologia; o Brasil tem uma tecnologia tropical desenvolvida e isso se deve a excelência das instituições de pesquisa como a EMBRAPA - Empresa Brasileira de Pesquisa Agropecuária, Institutos Estaduais de Pesquisa e Universidades; o terceiro fator é o humano; o agronegócio brasileiro é gerido por pessoas jovens cada vez mais qualificadas e empreendedoras, ao contrário dos países desenvolvidos onde as 


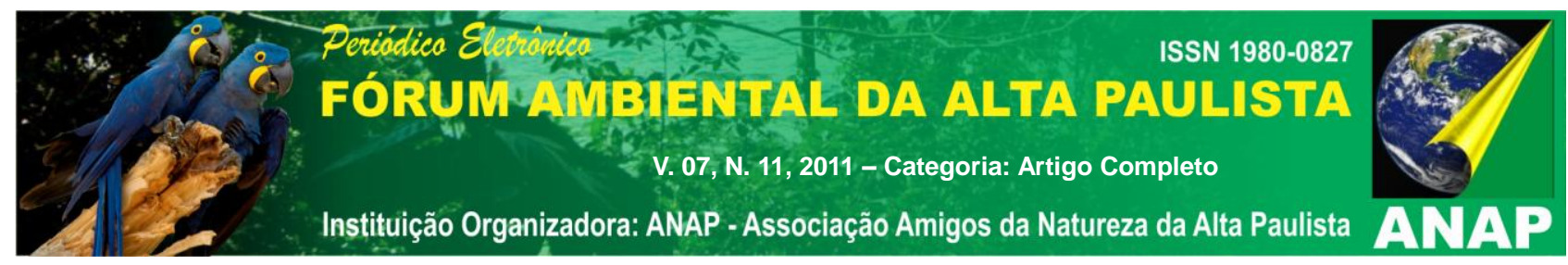

populações agrícolas estão envelhecendo porque os jovens não querem se dedicar a essa atividade.

Mesmo o agronegócio sendo um setor em grande parte ligado a produção e à agricultura, seus elos perpassa e impacta por praticamente todos os setores da economia. Para cada elo, entre insumos, produção, beneficiamento/industrialização, distribuição e consumo, há algum tipo de serviço sendo realizado como a interface essencial entre "produto x cliente" de todos os níveis. A realização de um serviço eficiente e eficaz torna-se peça fundamental para a sustentação de toda a cadeia agroindustrial. Ou seja, a aplicação, a visão científica/metodológica para a criação de modelos, simuladores ou métodos para a concepção de serviços torna-se parte essencial e estratégica.

A aplicação de CS no agronegócio para este artigo limita-se à interface comum entre "comprador x vendedor" objetivando fortalece-lo com base na análise científica prévia de serviços como um fator diferencial e competitivo no agronegócio nacional, reduzindo perdas, custos e tempo tanto no transporte (inputs e outputs) de mercadoria/produto como no fluxo de divisas entre os agentes.

\section{CONSIDERAÇÕES FINAIS}

Procurou-se mostrar a importância da Ciência de Serviço, suas inovações e a possibilidade e necessidade de se criar um novo ramo de aplicações na área do agronegócio brasileiro.

Esta Ciência, que mostra necessidades de criações de políticas públicas, pode vir a ser uma inovação quando aplicada nestes complexos agroindustriais, desde ações que visem sistematizar os procedimentos de produtores rurais frente aos serviços necessários para 0 andamento de sua propriedade (como manutenção/vacinação da gado, busca de mão-de-obra especializada para operações em máquinas de lavouras, etc), de consumidores destes produtos primários (como indústrias de processamento de amendoim, frigoríficos, etc) e também o consumidor final, via redes atacado e/ou varejo.

Os serviços existentes entre os elos do sistema agroindustrial são de suma 


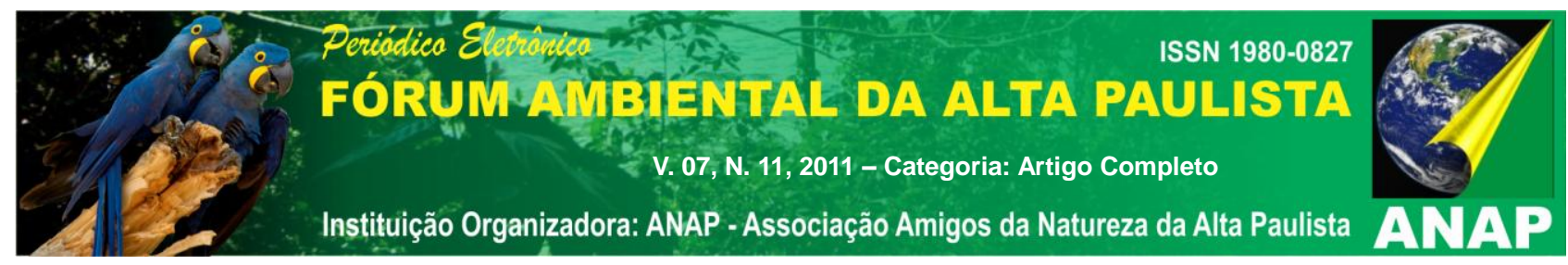

importância no estabelecimento do custo final, na formação de parceiros comerciais e na eficiência do serviço.

Desta forma, com os apontamentos apresentados sobre o desenvolvimento da Ciência de Serviços e suas possíveis atuações no crescente ramo do agronegócio brasileiro, pode-se afirmar que esta linha de pesquisa precisará de investimentos governamentais e privados para seu urgente desenvolvimento, sendo que uma variedade de profissionais como agrônomos, economistas, administradores, engenheiros entre outros, podem vir a atuar de modo interdisciplinar na área visto sua importância e posicionamento estratégico na economia brasileira e internacional.

\section{REFERÊNCIAS}

BATALHA, M. O. Gestão agroindustrial. 2. ed. São Paulo: Atlas, 2001

BARANIUK, J. A. Modelo de Gerenciamento de Serviços, Utilizando o Valor do Cliente no Tempo: Uso de Mineração de Dados em um Serviço de Telecomunicações. 296 f., Tese de Doutorado. Centro de Pesquisa e PósGraduação em Administração, Universidade Federal do Paraná, Curitiba, 2009.

CARLOS L.; BARBOSA L. "Evolução do agronegócio brasileiro, desafios e perspectivas" en Observatorio de la Economía Latinoamericana, Número 118, 2009.

CEPEA/USP - Centro de Estudos Avançados em Economia Aplicada. http://www.cepea.esalq.usp.br/. Acesso em 01 de fevereiro de 2011.

CIÊNCIA DE SERVIÇOS. http://www.cienciadeservicos.com.br/index.htm. Acesso em 01 de fevereiro de 2011.

DAVIS, J. H; Goldberg, R. A. A concept of agribusiness. Boston: Harvard University. 1957. $135 \mathrm{p}$.

IfM and IBM. Succeeding through Service Innovation: A Service Perspective for Education, Research, Business and Government. Cambridge, United Kingdom: University of Cambridge Institute for Manufacturing, 2008. ISBN: 978-1-902546-65-0.

ING, D. Business models and evolving economic paradigms: a systems science approach. Proceedings of the 52nd Annual Meeting of the ISSS. http://journals.isss.org/index.php/proceedings52nd/article/view/1022. Acesso em: 04 


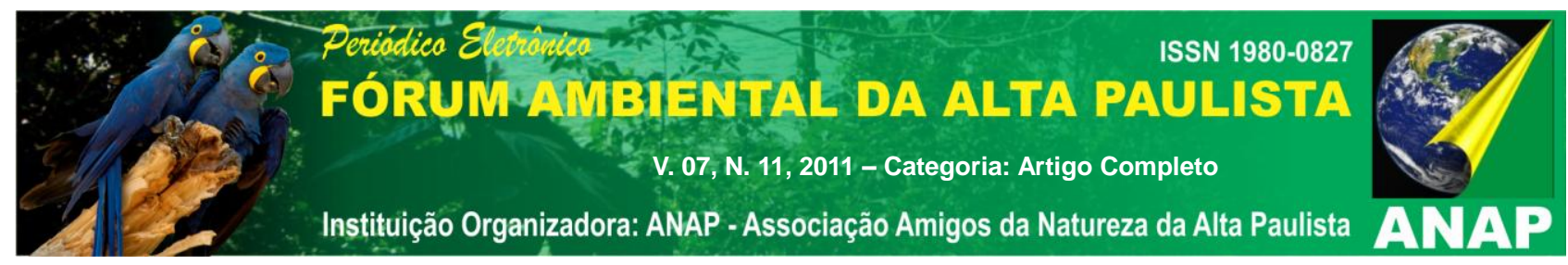

de abril de 2011.

GUILHOTO, J. J. M.; SILVEIRA, F. G.; ICHIHARA, S. M.; AZZONI, C. R. A importância do agronegócio familiar no Brasil. Rev. Econ. Sociol. Rural [online]. 2006, vol.44, n.3, pp. 355-382 .

GUNDERSON, M. A.; GRAY, A. W; AKRIDGE, J. T. Service quality in agronomic inputs: does the hierarchical model apply?. Agribusiness, 25:500-519. 2009. doi: 10.1002/agr.20222

KOTLER, P. Administração de Marketing. 10 ed. São Paulo: Prentice Hall, 2000.

KUBOTA, L. C. A Inovação Tecnológica das Firmas de Serviços no Brasil. In: Estrutura e Dinâmica do Setor de Serviços no Brasil. Edited by J. A. Negri and L. C. Kubota. Brasilia: IPEA, 2006.

LOVELOCK, C; WRIGHT, L. Serviços: marketing e gestão. São Paulo: Saraiva, 2001.

MAPA - Ministério da Pecuária, Agricultura e Abastecimento (2011). http://www.agricultura.gov.br/. Acesso em 10 de fevereiro de 2011.

PIB AGRONEGÓCIO. CEPEA-USP/CNA. http://www.cepea.esalq.usp.br/pib/. Acesso em 01 de fevereiro de 2011.

PINHANEZ, C. S. Educação e pesquisa em ciência de serviços no Brasil: necessidade e oportunidade. Revista Competência da Educação Superior do SENAC-RS, v. 2(2), 2009.

PINHANEZ, C. "Humans Inside" as the Key Characteristic of Service Systems, In: QUIS 11 - Moving Forward with Service Quality, Wolfsburg, Germany, p. 515-524, 2009. 